\title{
Low volatility sector-based portfolios: a South African case
}

\author{
OS Oladele* $\quad$ D Bradfield ${ }^{\dagger}$
}

Received: 22 June 2015; Revised: 29 February 2016; Accepted: 2 March 2016

\begin{abstract}
Portfolios and indices that have been specifically constructed to have low risk attributes have received increasing interest in the recent international literature. It has been found that portfolios constructed by targeting low risk assets have predominantly outperformed portfolios constructed to have higher risks. This anomaly has led to renewed interest in constructing low volatility portfolios by practitioners. This study analyses a variety of low volatility portfolio construction methodologies using sectors as building blocks in the South African environment. The empirical results from back-testing these portfolios show significant promise in the South African setting when compared with a market capitalization-weighted benchmark. In the empirical analysis in the South African environment two techniques stand out as being superior low volatility construction techniques amongst the seven techniques assessed. Furthermore, the low volatility portfolios are blended with typical general equity portfolios (using the Shareholder-Weighted Index (SWIX) as a proxy). It was found that these blended portfolios have useful features which lead to enhanced performance and therefore can serve as effective portfolio strategies.
\end{abstract}

Key words: Low volatility portfolios, Minimum Variance (MVP), Low Volatility Single Index Model (SIM), Equal Risk Contribution (ERC), Naïve Risk Parity (NRP), Maximum Diversification (MDP), Equal Weighting (EW), Covariance Bi-plot.

\section{Introduction}

Support for the low volatility anomaly stems from the criticism of the Capital Asset Pricing Model (CAPM), which states that assets with high systematic risk are expected to earn higher expected returns, while low beta assets are expected to have lower returns $[33,40]$. However, evidence of a low volatility anomaly was first discovered by Black [3] who demonstrated empirically that the security market line is flatter than predicted by the

\footnotetext{
${ }^{*}$ Department of Statistical Sciences, University of Cape Town, 7700 Rondebosch, South Africa

${ }^{\dagger}$ Corresponding author: Department of Statistical Sciences, University of Cape Town, 7700 Rondebosch, South Africa, email: david.bradfield@uct.ac.za
} 
CAPM. Black pointed out that when investors are restricted from using leverage or borrowing, they tend to buy high-risk assets thereby leaving the low-risk assets under-priced. This evidence has led to an increasing interest in the formation of low volatility portfolios that not only have lower risks out-of-sample than market-cap-weighted portfolios, but also have higher risk-adjusted returns out-of-sample than market-cap-weighted portfolios.

Recently, Baker et al. [2] gave some behavioral reasons as to why some investors may create an excess demand for high-risk stocks that have historically underperformed. They also argued why investors might typically avoid buying low-risk stocks. The reasons Baker et al. [2] put forward were:

- Investors preference for lottery-like payoffs; implying that investors accept a low probability of receiving a large windfall.

- Representativeness bias, which suggests that investors prefer high-risk stocks that contain a lot of news. Hence, they buy the stock at a high price, which in turn lowers the return of the stock.

- Portfolio managers are required to beat a specific benchmark and to minimize the tracking error relative to that benchmark. Hence, they are averse to investing in low beta stocks, because of their high tracking error relative to the benchmark.

The primary objective of this study is to assess the performance of low volatility portfolios constructed from indices relative to the market capitalization-weighted indices using the FTSE/JSE sectors. The use of sectors for portfolios was motivated by Leclerc et al. [25], who created industry-based weighting schemes in the U.S. markets. Leclerc et al. [25] named their industry-based weighting scheme Alternative Equity Indices (AEI's) which were designed as alternatives to market capitalization-weighted portfolios. Leclerc et al. [25] gave the following reasons for using sectors to construct low volatility portfolios rather than stocks: Firstly, constructing portfolios based on sectors help in overcoming the curse of dimensionality as explained by Michaud [35]. That is, the number of parameters to estimate is reduced. Secondly, even though some stock-constituent AEI's may outperform the sector-based AEI's before transaction cost, the sector-based AEI's are still considered a reasonable choice in terms of capacity, transparency, liquidity and resultant transaction costs. Lastly, sector tilts are important in explaining constituent-based stocks outperformance over the market capitalization indices.

In brief, the study involves the assessment of a range of sector-based low volatility techniques found in recent literature for constructing portfolios. These portfolios are rebalanced monthly using a 36 months rolling window to estimate the covariance matrix. Additionally, the Ledoit \& Wolf [26] shrinkage covariance estimator is used to reduce the effect of errors in the sample covariance matrix. The performances of the sector-based low volatility portfolios are then compared with the ALSI (the market capitalization-weighted benchmark).

The main contributions of this article are: Firstly, different portfolio construction techniques for forming the low volatility portfolios (based on sectors) are demonstrated and assessed in the South African equity market. Secondly, the Ledoit \& Wolf [26] covariance shrinkage estimator is utilised in the portfolio construction process of the portfolios. Finally, sector-based low volatility portfolios are blended (with the Shareholder-Weighted Index (SWIX)) in order to establish their usefulness as a combined portfolio strategy. 
This article is organized as follows. In the first section, the literature pertinent for the study is reviewed. The second section discusses the data and methodology together with the parameter estimation (shrinkage techniques) used for constructing the covariance matrix. The third section covers the empirical results derived from the back-testing of the sectorbased low volatility portfolios. The fourth section discusses the empirical results from the blending of the sector-based low volatility portfolios with the SWIX index. Lastly, the fifth section summarizes the major conclusions in this study.

\section{Literature review}

Mean-variance optimization is a process whereby investors seek to effectively allocate investments by choosing a portfolio on the efficient frontier [31, 32, 33]. Lintner [28] and Sharpe [40] extended the work of Markowitz on portfolio selection by introducing the Capital Asset Pricing Model (CAPM), where they argued that the market capitalizationweighted portfolio is expected to be the optimal portfolio. In the same vein, Siegel [41] discussed the characteristics of an index weighted by market capitalization. He argued that the market capitalization weighting is the central principle of good index construction and gave the following reasons: Firstly, the market capitalization-weighting is the only weighting scheme consistent with the buy-and-hold strategy. Secondly, it doesnt require a portfolio to be constantly rebalanced. Thirdly, the market capitalization-weighted index is the only portfolio that is expected to be mean-variance efficient. That is, all investors should hold the market portfolio according to the CAPM. Finally, it has low turnover and transaction costs.

However, market capitalization-weighted indices suffers from various pitfalls including the underlying unrealistic assumptions of the CAPM (including homogeneous return expectations, frictionless markets, perfectly divisible assets and equal borrowing and lending rates). For example, Fama \& French [15] and Roll \& Ross [39] found evidence of an inefficient tradeoff of the risk-return relation of the CAPM. In addition, the market capitalization-weighted portfolio tends to suffer from concentration in the largest securities in the portfolio, such that the contribution of the smallest capitalization securities will not be felt [24, 25]. Bradfield \& Kgomari [4] found evidence of high concentration in the JSE All Share Index (ALSI). They showed that a few companies that dominate the index have a high correlation with each other. Consequently, the risk of concentrated market capitalization-based portfolios tend to swamp out the effect of smaller asserts in the portfolio. Furthermore, mean-variance optimization has been shown to be associated with high estimation error which optimizers tend to gravitate towards [6, 26, 34, 35]. Small changes in the input parameters (especially estimates of expected returns) will have a significant effect on the optimal portfolio weights. Chopra \& Ziemba [6] went as far as suggesting that the performance of the portfolios could be improved by assuming that all assets have the same expected returns.

More recently, low volatility portfolios have been analyzed and have shown significant outperformance when compared with market capitalization-weighted indices $[1,5,9,10$, 18, 25]. With regards to the South Africa equity market, the first evidence of the low volatility anomaly in the South African equity market was documented by van Rensburg 
\& Robertson [43], where it was found that the beta of a stock is negatively related to its return. Recently, Kruger et al. [23] also found similar evidence of the low volatility anomaly using a more refined beta estimate. Furthermore, the performance of a variety of low volatility portfolios has also been assessed in out-of-period settings [21, 37]. Khuzwayo [21] for example found strong evidence in support of the low volatility anomaly in South Africa (using the Top 100 JSE stocks from 2001-2011). Khuzwayo showed that the low volatility portfolios constructed had a lower drawdown and also outperformed the market portfolio. Panulo [37] constructed risk parity portfolios and other risk-based portfolios which showed significant outperformance compared with the market capitalization-weighted index (All Share Index).

The sector-based low volatility portfolios examined in this article have been sourced from recent literature and they are: the Equally-Weighted (EW), the equal-weighted Low Beta (Lowbeta), the Minimum Variance Portfolio (MVP), the low Volatility Single Index Model (SIM), the Equal Risk Contribution (ERC), Naïve Risk Parity (NRP), and the Maximum Diversification Portfolio (MDP). Table 1 contains a summarised description of these portfolios as found in the literature.

\begin{tabular}{|c|c|c|c|}
\hline Techniques & Targets & Required parameter & Formula \\
\hline EW [14] & $\begin{array}{l}\text { Maximum weights } \\
\text { diversification }\end{array}$ & $\begin{array}{l}\text { No risk or return } \\
\text { parameter }\end{array}$ & $w_{i}=1 / N$ \\
\hline Lowbeta [25] & Low beta assets & Beta & $w_{i}=1 / N_{L}$ \\
\hline $\operatorname{MVP}[10,18]$ & $\begin{array}{l}\text { Low volatility assets } \\
\text { and low correlation }\end{array}$ & Covariance matrix & $w^{*}=\min \sum_{i=1}^{N} \sum_{j=1}^{N} w_{i} w_{j} \sigma_{i j}$ \\
\hline SIM [11] & $\begin{array}{l}\text { Low beta and low } \\
\text { volatility assets }\end{array}$ & $\begin{array}{l}\text { Beta and idiosyn- } \\
\text { cratic variance }\end{array}$ & $w_{i}=\frac{\sigma_{m v}^{2}}{\sigma_{i}^{2}\left(1-\frac{\beta_{i}}{\beta}\right)}$ \\
\hline ERC[29] & $\begin{array}{l}\text { Maximum risk } \\
\text { diversification }\end{array}$ & $\begin{array}{l}\text { Volatility and } \\
\text { correlation }\end{array}$ & $\min \sum_{i=1}^{N} \sum_{j=1}^{N}\left(w_{i} \frac{\partial \sigma_{p}}{\partial w_{i}}-w_{j} \frac{\partial \sigma_{p}}{\partial w_{j}}\right)^{2}$ \\
\hline NRP $[29,38]$ & $\begin{array}{l}\text { Assets with lower } \\
\text { volatilities than others }\end{array}$ & Volatility & $w_{i}=\frac{1 / \sigma_{i}}{\sum_{i=1}^{N}} 1 / \sigma_{i}$ \\
\hline $\operatorname{MDP}[7,8]$ & $\begin{array}{l}\text { Low correlation with } \\
\text { other assets }\end{array}$ & $\begin{array}{l}\text { Volatility and } \\
\text { correlation }\end{array}$ & $w^{*}=\arg \max \frac{w_{i} \sigma}{\sigma_{p}}$ \\
\hline
\end{tabular}

Table 1: A summary of the low volatility portfolios.

To be consistent with developments in the mean-variance framework of Markowitz [31], it is noted that all of the authors mentioned in Table 1 were concerned with low standard deviation or variance of return, rather than some other measure of risk, for example semivariance (downside risk). It is pointed out that portfolios targeting semi-variance should be the same as those targeting variance if the underlying distributions are symmetrical. Whilst low semi-variance may be an interesting metric to target, it is left to directions for further research and we thus focus on the standard deviation of returns instead in this article. As standard deviations are couched in the same units as returns, refer to annualised risk as being the annualised standard deviation of returns.

\subsection{The different low volatility construction methodologies}

In this section, the construction of the sector-based low volatility portfolios (as summarized in Table 1) is briefly discussed and their performance as reported in the literature is reviewed. 


\subsubsection{The naïve equally-weighted portfolio}

The first methodology, the naïve equally-weighted portfolio (EW), assigns an equal weight to each sector. For a universe of $N$ sectors, the EW portfolio assigns weights equally and is given by

$$
w_{i}=1 / N
$$

where $w_{i}$ are the portfolio weights of sector $i$ with $i=1,2, \ldots, N$.

The EW technique in essence assumes that the risk and return cannot be forecasted [27]. This strategy thus helps to reduce the impact of concentration of risk by having equal weights. Thus, with the EW strategy investors are equally exposed to the smallest sectors as well as the largest sectors in the portfolio.

DeMiguel et al. [14] analyzed 7 empirical datasets of monthly returns using the U.S. small-, mid- and large-cap indices and compared the out-of-sample performance of 14 different models. They found that the benefits of optimal portfolio strategies are more than offset by estimation errors. Consequently, none of the 14 different models performed better than the naïve equal weighting strategy.

\subsubsection{The equal-weighted low beta portfolio}

The equal-weighted low beta portfolio (Lowbeta) is formed by equal weighting those sectors with the lowest $20 \%$ of betas. It is given by

$$
w_{i}=1 / N_{L},
$$

where $N_{L}$ is the number of sectors in the Lowbeta portfolio.

The intuition for using the Lowbeta portfolio for the sectors was motivated by the works of Black [3] and Haugen \& Heins [19] who showed that low-beta stocks have historically outperformed high-beta stocks. In the same vein, Frazzini \& Lasse [16] and Frazzini \& Pedersen [17] also found outperformance of low-beta stocks over the high-beta stocks in their betting versus beta factor strategy. Recently, Khuzwayo [21] computed low-beta versus high-beta stocks using the Top 100 JSE shares over the period 2001 to 2011 and compared their performance with the All Share Index (ALSI). He found that during the sample period, the low-beta portfolios outperformed both high-beta portfolios and the ALSI.

\subsubsection{The minimum variance portfolio}

The Minimum Variance Portfolio (MVP) is the portfolio located on the left-most position of the efficient frontier, and is made up of the least volatile joint collection of assets [10, 18]. The objective function of the MVP is to minimize total portfolio risk and is given by

$$
w^{*}=\min \sum_{i=1}^{N} \sum_{j=1}^{N} w_{i} w_{j} \sigma_{i j},
$$

where $\sigma_{i j}$ is the covariance between the returns of sectors $i$ and $j$. 
The MVP portfolio is considered more robust than the optimal portfolio (in mean-variance space as defined by Markowitz [31]) because of the optimal portfolios sensitivity to inputs in the forecast return vector and the covariance matrix [6, 26, 34, 35]. Clarke et al. [10] constructed portfolios using the MVP technique and found higher realized average returns and lower risks than the market return by using shrinkage methods ${ }^{1}$ applied to the sample covariance matrix using large-cap U.S. stocks over the periods 1968 to 2009. Jagannathan \& Ma [20] also constructed MVPs by imposing weight constraints and found them equivalent to using a shrinkage estimator on the variance-covariance matrix. Kritzman et al. [22] found higher Sharpe ratios in their MVP techniques constructed relative to the EW and market capitalization-weighted indices. Similarly, Haugen \& Baker [18] also showed that the MVP technique outperformed the Wilshire 5000 at a lower risk between the periods 1972 to 1989.

\subsubsection{The low volatility single index model}

The low Volatility Single Index Model (SIM) was proposed by Clarke et al. [11]. They derived an analytic solutions for the positive weights (long-only portfolios) using Sharpes single-index model [40] for their minimum variance portfolio construction. The SIM technique assumes that the only common source of risk is a single factor (the market portfolio). Using the decomposition of an assets risk into the idiosyncratic risk and the systematic risk, [11] derived the SIM weights as

$$
w_{i}=\frac{\sigma_{m v}^{2}}{\sigma_{e i}^{2}}\left(1-\frac{\beta_{i}}{\beta_{L}}\right) \text { for } \beta_{i}<\beta_{L} \text { else } w_{i}=0,
$$

where $\beta_{L}$ is the beta-bound (threshold beta) of the long-only assets, $\beta_{i}$ is the beta of the asset to the common factor (the market), $\sigma_{m v}^{2}$ is the ex-ante variance of the long-only SIM minimum variance portfolio, and $\sigma_{e i}^{2}$ is the ex-ante idiosyncratic variance for asset $i$.

The equation above suggests that the portfolio weights are highly dependent on the betas and idiosyncratic risk. However, Clarke et al. [11] argued that the idiosyncratic risk will not drive the asset out of the solution. In addition, the equation also targets those assets with betas that are lower than the long-only threshold beta $\left(\beta_{L}\right)$. The formula for calculating $\beta_{L}$ is given by

$$
\beta_{L}=\frac{\frac{1}{\sigma_{m}^{2}}+\sum_{\beta_{i}<\beta_{L}} \frac{\beta_{i}^{2}}{\sigma_{e i}^{2}}}{\sum_{\beta_{i}<\beta_{L}} \frac{\beta_{i}}{\sigma_{e i}^{2}}},
$$

where $\sigma_{m}^{2}$ is the market variance.

The method for calculating $\beta_{L}$ is to first sort the betas of sectors in ascending order, then the beta of each sector is compared with the cumulative summation term until the beta of the sector exceeds the cumulative right-hand-side (RHS) value yielding the required threshold beta.

Clarke et al. [11] compared SIM portfolios, with other low volatility portfolios using 1000 U.S. stocks over the period 1968 to 2012 and then compared these with the market cap-

\footnotetext{
${ }^{1}$ They used both Asymptotic Principal Component by Connor \& Korajczyk [13] and Bayesian shrinkage estimation of Ledoit \& Wolf [26].
} 
italization weighted portfolio. They found that the SIM portfolio posted the lowest risk and the highest Sharpe ratios. Additionally in South Africa Khuzwayo [21] found higher Sharpe ratios for the SIM portfolios when compared with the performance of the MVP, MDP, EW portfolios as well as the ALSI 100 during the periods 2008 to 2011.

\subsubsection{The equal risk contribution portfolio}

The Equal Risk Contribution portfolio (ERC) aims to allocate risk equally among sectors. Qian [38] for example found that equities contribute over $90 \%$ of the risk of a $60 / 40$ (equity/bond) portfolio resulting in a large concentration of risk in the portfolio. The ERC portfolios instead allocates weight to sectors by their contribution to risk and thus takes into account the correlation between the sectors in a portfolio. As a result, the ERC portfolio targets risk diversification by focusing on sectors with low volatility and low correlation with other assets [27, 29]. The ERC portfolio derived by Maillard et al. [29] computes the portfolio weights using a sequential quadratic programming as

$$
w^{*}=\arg \min \sum_{i=1}^{N} \sum_{j=1}^{N}\left(w_{i} \frac{\partial \operatorname{MCR}_{p}(w)}{\partial w}-w_{j} \frac{\partial \operatorname{MCR}_{p}(w)}{\partial w}\right)^{2},
$$

where $w_{i} \frac{\partial \mathrm{MCR}_{p}(w)}{\partial w}$ is the risk contribution to the portfolio (the weights of the sectors in the portfolio multiplied by the marginal risk contribution to the portfolio).

From equation (6), the ERC portfolio will allocate higher weight to sectors that have low correlation and volatility with other sectors. Maillard et al. $[29,30]$ compared the EW, ERC, MDP and MVP using equity U.S. sectors. They found that all strategies, except the EW, outperformed the market capitalization portfolio with a lower volatility. They also showed that the volatility of the ERC portfolio is located between the EW portfolio and the MVP.

\subsubsection{The naïve risk parity portfolio}

In contrast to the ERC technique, the Naïve Risk Parity (NRP) technique, assumes that all sectors have the same pair-wise correlations. The optimal portfolio weights are computed analytically and can be expressed as

$$
w_{i}=\frac{1 / \sigma_{i}}{\sum_{i=1}^{N} 1 / \sigma_{i}},
$$

where $\sigma_{i}$ is the volatility of sector $i$. From equation (7), it follows that sectors that are more risky than others will receive a lower weight in the portfolio.

\subsubsection{The maximum diversification portfolio}

Finally, the Maximum Diversification Portfolio (MDP) technique is examined, which is constructed to maximize a diversification ratio as derived by Choueifaty \& Coignard [7]. 
The diversification ratio is defined as the ratio of the weighted average of volatility to the portfolio volatility and is given by

$$
w^{*}=\arg \max \frac{\sum w_{i} \sigma_{i}}{\sigma_{p}},
$$

where $\sigma_{i}$ is the volatility of an individual asset and $\sigma_{p}$ is the portfolio volatility.

From the equation above, the MDP technique will rather allocate weight based on the asset's correlation with the portfolio. This suggests that the MDP portfolio will invest in sectors that are less correlated to the portfolio, which will in turn, increases the diversification ratio. Choueifaty \& Coignard [7] investigated the performance of the MDP, with the EW and the MVP portfolios using constituents stocks from S\&P 500 and Dow Jones EURO STOXX Large Cap indices over the period 1992-2007. They showed that the MDP produced the highest return.

\subsection{Covariance matrix estimation}

At the heart of the sector-based low volatility portfolio strategies is the estimation of the covariance matrix. The covariance matrix is an important input source that plays a central role in producing the optimal portfolio weights. Thus, small changes in input assumptions of the covariance matrix may imply large changes in the portfolio weights. Michaud [35] proposed using resampling methods to estimate the mean and covariance terms. Ledoit \& Wolf [26] derived a shrinkage transformation on the sample covariance matrix and applied it to monthly U.S. stock data. They showed that the shrinkage estimator reduces the tracking error relative to the benchmark index. Clarke et al. [10] used both the Ledoit \& Wolf [26] Bayesian shrinkage estimator (Constant Correlation Model) and the Connor \& Korajczyk [13] asymptotic principal component method in implementing their minimum variance optimization. They found that the Bayesian shrinkage estimator produces a better result than the asymptotic principal component approach. In the South African environment Munro \& Bradfield [36] compared the performance of different shrinkage estimators (the Constant Correlation Shrinkage Model, the Single Index Model, the Principal Component Model, and the Average Covariance Model). They found that the Constant Correlation Model produced the lowest risk when using the MVP framework.

On the basis of the findings of Munro \& Bradfield [36], the Ledoit \& Wolf [26] Bayesian shrinkage estimator was adopted to estimate the covariance matrix in the ensuing empirical study. The Ledoit \& Wolf [26] Bayesian shrinkage technique involves finding a compromise between the sample covariance matrix $S$ and a shrinkage target (highly structured estimator $F$ ). They found a convex linear combination of both $S$ and $F$ as

$$
\Omega^{*}=\mu F+(1-\mu) S
$$

where $\mu$ is a shrinkage constant between 0 and 1 . In the Ledoit \& Wolf [26] case, the highly structured estimator used as the shrinkage target is the Constant Correlation Model. 


\section{Data and methodology}

The sample data used for analysis cover the 9 FTSE/JSE sectors from January 2003 to December 2013, which were collected from Datastream.

\subsection{Description of the data}

The 9 FTSE/JSE sectors in the data are the Oil and Gas, Basic Materials, Consumer Goods, Health Care, Consumer Services, Telecoms, Financials, Industrials, and the Technology sectors. The monthly total return indices were adjusted for all corporate actions. Table 2 describes the annualised return, annualised risk, Sharpe ratio (assuming a risk free rate of $8.43 \%$ ), and drawdown ${ }^{2}$ for the FTSE/JSE sectors.

\begin{tabular}{lrrrr}
\hline FTSE/JSE sectors & $\begin{array}{r}\text { Annualised } \\
\text { return }\end{array}$ & $\begin{array}{r}\text { Annualised } \\
\text { risk }\end{array}$ & $\begin{array}{r}\text { Annualised } \\
\text { Sharpe }\end{array}$ & Drawdown \\
\hline Oil and Gas & $16 \%$ & $25 \%$ & 0.27 & $44 \%$ \\
Basic Materials & $10 \%$ & $25 \%$ & 0.05 & $53 \%$ \\
Consumer Goods & $24 \%$ & $21 \%$ & 0.68 & $38 \%$ \\
Health Care & $26 \%$ & $19 \%$ & 0.88 & $37 \%$ \\
Consumer Services & $29 \%$ & $18 \%$ & 1.05 & $30 \%$ \\
Telecoms & $28 \%$ & $23 \%$ & 0.77 & $39 \%$ \\
Financials & $18 \%$ & $17 \%$ & 0.5 & $46 \%$ \\
Technology & $24 \%$ & $28 \%$ & 0.49 & $48 \%$ \\
\hline
\end{tabular}

Table 2: Descriptive statistics for the 9 FTSE/JSE sectors from January 2003 to December 2013 .

Figure 1 shows the correlation matrix between the 9 sectors. From Figure 1, it is evident that there is a high correlation between the Oil and Gas, Basic Materials, and Consumer Goods and the ALSI.

\subsection{Methodology}

The low volatility portfolios are rebalanced monthly over the period 2003-2013 for the sectors, assuming a trading cost of 25 basis points (bps). The general methodology follows the approach of Snopek [42] in the construction of the minimum variance portfolio. Additionally the following constraints are imposed.

- Fully invested constraint in the risky portfolio, that is $\sum_{i=1}^{N} w_{i}=1$.

- Long-only constraint $\left(w_{i} \geq 0\right)$.

Figure 2 depicts the methodology for constructing the low volatility portfolios. From Figure 2, the first covariance estimation period takes is from $t_{0}=$ January 2003 to $t_{1}=$ December 2005. The in-sample weights as at December 2005 are then multiplied by the out-of-sample 1 month return i.e. for January 2006, resulting in the portfolio return for

\footnotetext{
${ }^{2}$ Drawdown is defined to be the worst cumulative loss that a sector sustained, taken over the whole period of the analysis.
} 


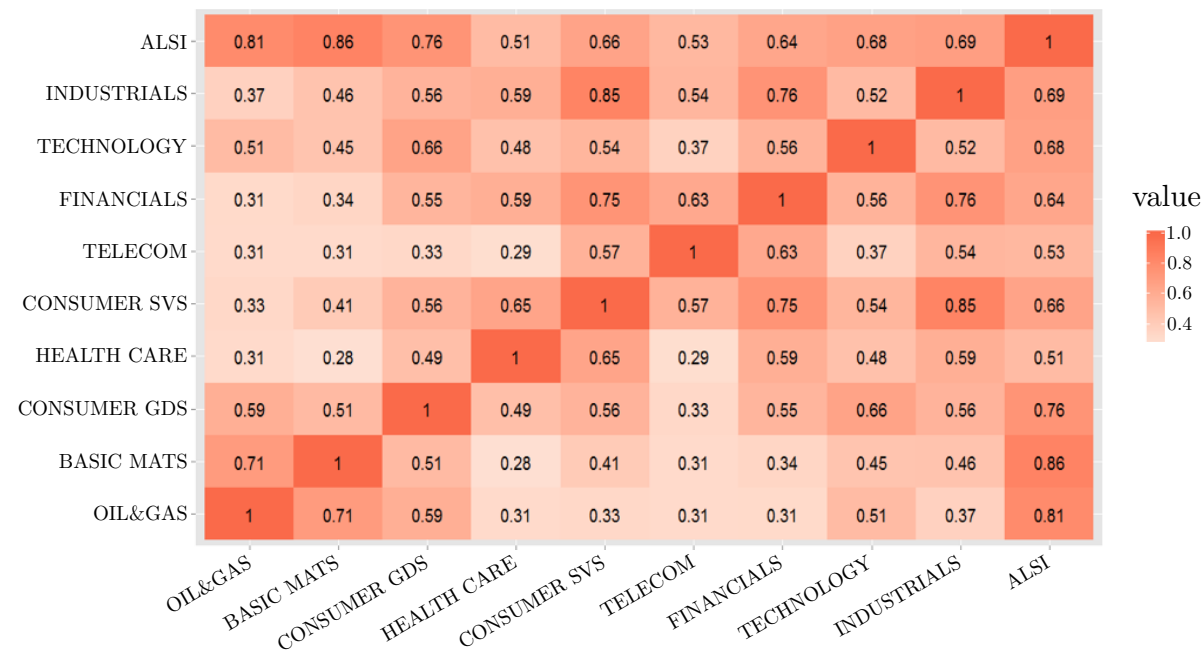

Figure 1: Correlation matrix for the FTSE/JSE sectors for January 2003 to December 2013.

that month. The entire process is then rolled forward 1 month, from $t_{0}^{\prime}=$ February 2003 to $t_{1}^{\prime}=$ January 2006. This procedure is rolled forward monthly repeatedly until the end of data period is reached, at December 2013. Additionally in the estimation period, the low volatility portfolios that will require construction by optimization are the MVP, ERC, and the MDP portfolios. The EW, Lowbeta, NRP, and SIM portfolios do not require optimization. Recalculation of the betas is, however, required for constructing both the Lowbeta and SIM portfolios. The historical betas are estimated using the standard ordinary least square estimates of the previous 36 months, where the common market factor is the ALSI. For the Lowbeta portfolio, equal weights are assigned to sector betas lower than 50 th percentile beta $(\leq 50 \%)$.

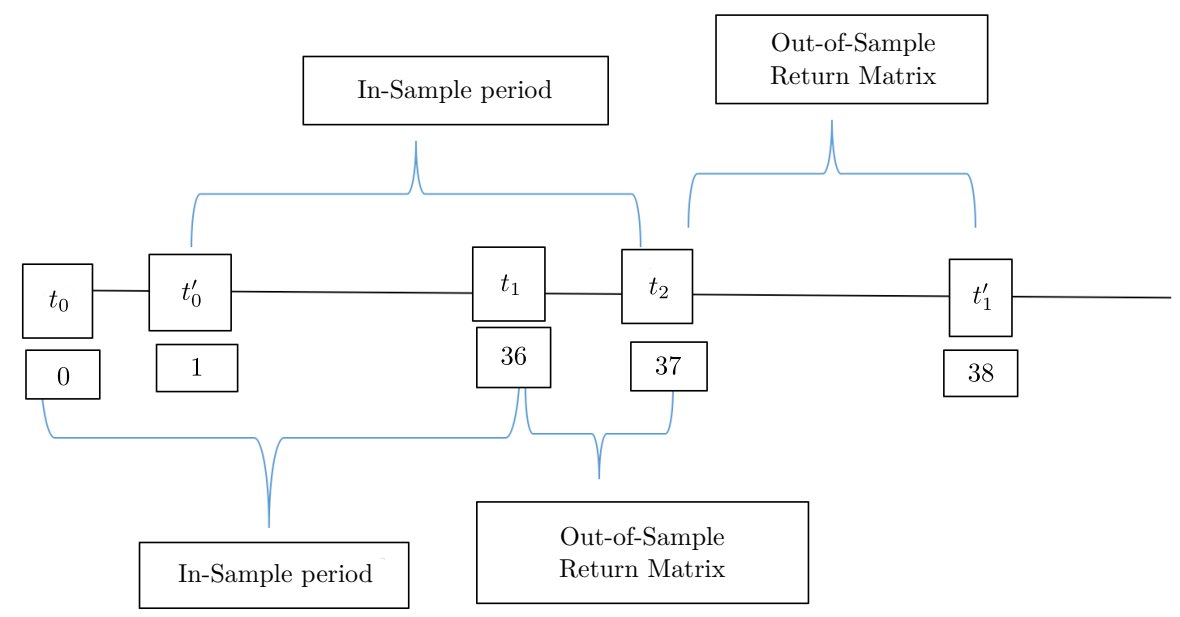

Figure 2: Methodology for the monthly rebalancing on the FTSE/JSE sectors adapted from Snopek [42]. 


\section{Empirical performance}

Table 3 reports the out-of-sample performance statistics for the low volatility portfolios after accounting for rebalancing cost (assumed to be 25bps) at each rebalancing date, from January 2006-December 2013. The Gini Weight measures the average sector weight concentration while the Gini Risk measures the average sector risk decomposition for the low volatility portfolios. The Gini index is a measure of dispersion using the Lorenz curve [29]. The Lorenz curve is a graphical representation of the cumulative distribution of the distribution of wealth in a society, where the statistics of interest may be the income of a population. Mathematically, the Gini index $G$ is computed as $G=1-2 \int_{0}^{1} L(x) d x$ where $L(x)$ is the Lorenz curve. Applying this concept to the low volatility portfolios, the statistics of interest become the weights and risk contributions of a portfolio.

\begin{tabular}{lrrrrrrrrr}
\hline & Lowbeta & SIM & MDP & NRP & ERC & EW & MVP & SWIX & ALSI \\
\hline Annualised Return & $23 \%$ & $21.4 \%$ & $21.5 \%$ & $20.6 \%$ & $20.5 \%$ & $20.3 \%$ & $20.1 \%$ & $16.7 \%$ & $16.3 \%$ \\
Annualised Risk & $15 \%$ & $15.3 \%$ & $15.7 \%$ & $14.8 \%$ & $14.9 \%$ & $15 \%$ & $15.4 \%$ & $15.8 \%$ & $17.1 \%$ \\
Annualised Sharpe & 0.86 & 0.78 & 0.75 & 0.74 & 0.73 & 0.71 & 0.69 & 0.52 & 0.41 \\
Drawdown & $31 \%$ & $33 \%$ & $37 \%$ & $32 \%$ & $32 \%$ & $31 \%$ & $37 \%$ & $36 \%$ & $41 \%$ \\
Beta & 0.7 & 0.69 & 0.76 & 0.79 & 0.8 & 0.81 & 0.76 & 0.89 & \\
Correlation (ALSI) & 0.79 & 0.79 & 0.84 & 0.91 & 0.92 & 0.92 & 0.84 & & \\
Correlation (SWIX) $^{3}$ & 0.82 & 0.87 & 0.97 & 0.96 & 0.96 & 0.94 & 0.89 & & \\
Information Ratio $^{3}$ & $63 \%$ & $48 \%$ & $41 \%$ & $61 \%$ & $62 \%$ & $60 \%$ & $41 \%$ & $10 \%$ & \\
No. of Sectors & 5 & 6 & 7 & 9 & 9 & 9 & 6 & 9 & 9 \\
Gini Weight & 0.44 & 0.52 & 0.63 & 0.11 & 0.1 & 0 & 0.63 & 0.55 & 0.49 \\
Gini Risk & 0.49 & 0.51 & 0.63 & 0.08 & 0.06 & 0.11 & 0.63 & 0.4 & 0.57 \\
\hline
\end{tabular}

Table 3: Out-of-sample performance measures of the low volatility portfolios relative to the ALSI from January 2006 to December 2013.

The low volatility portfolios are also ranked from the highest Sharpe ratios to the lowest Sharpe ratios. Appendix A also depicts the evolution of the sector weights and risk contribution of each sector over the 2006-2013 test period. In addition, Appendix B shows the average sector weights and the last known weights of each sector in the low volatility portfolios.

From Table 3, it is evident that all of the portfolios outperformed the ALSI in terms of lower risk and higher Sharpe ratios. More salient is the high Sharpe ratio of the Lowbeta (0.86) and the SIM (0.78) portfolios over the period. Furthermore, the portfolios also showed a lower drawdown than the ALSI. The Lowbeta portfolio also posted the lowest drawdown of 0.31, whereas the MVP and SIM portfolio had the highest drawdown of 0.37 amongst the low volatility portfolios. Note that the SIM, and the Lowbeta had a high tracking error ${ }^{4}(11 \%)$ relative to the ALSI, whereas, the ERC, NRP, MDP, MDS, and EW techniques posted a lower tracking error relative to the ALSI. Interestingly these portfolios that have been constructed on the basis of in-sample betas have preserved these

\footnotetext{
${ }^{3}$ The information ratio of a portfolio is the active premium (portfolio annualised return minus benchmark annualised returns) divided by the tracking error.

${ }^{4}$ The tracking error of a portfolio is the standard deviation of the difference between the portfolios returns and the benchmark returns.
} 
low beta characteristics out-of-sample (for example the betas of the Lowbeta (0.7), MVP (0.76), and SIM (0.69) techniques were the lowest of all portfolios). As with Maillard et al. [30] Gini statistics are included in Table 3. Regarding the interpretation of the Gini statistics, it is noted that the Gini statistic takes on the value of 1 for a perfectly concentrated portfolio and 0 for an equally-weighted one. In essence the closer to zero, the less concentrated are the weights (and risk contributions), and the closer to one, the more concentrated the weights and risks contributions are. For the Gini risks, instead of using weights, the contribution to portfolio risks is calculated instead (weights of sectors multiplied by the marginal risk contribution). Once more the Gini risk for a portfolio is proportional to its risk contribution mapped out by the Lorenz curve.

Furthermore, the Gini Weight, and Gini Risk from Table 3 suggests that:

- The Gini Weight for the ALSI had a weight of 0.49 and Gini Risk of 0.57. Basic Materials, Financials and Consumer Goods were the dominant sectors in the index while the Technology, Health care, Oil and Gas, Consumer Services and Industrials were the least dominant sectors (see Figure A.1).

- The Gini Weights for the MVP, and SIM techniques (0.63 and 0.52) were relatively more concentrated (see Figure A.2 and A.3), with Gini Risks of 0.63 and 0.51 respectively. This perhaps is not surprising, given that the minimum variance strategy assigns weights to low beta sectors specifically the Consumer Goods, Health care, Financials and Industrials.

- For the Lowbeta portfolio, the Gini Weight and Gini Risk (0.44 and 0.49) were lowest respectively (less concentrated). The Lowbeta portfolio is dominated by low beta sectors, thus over the sample period, Financials, Health care, Consumer goods, Consumer services, and Industrials were mostly included in the equal weight low beta portfolio (see Figure A.8).

- The Gini Weights for the EW, ERC and NRP techniques (0, 0.10 and 0.11 respectively) have the lowest concentration. For the EW technique, all sectors were given equal weight (see Figures A.4, A.5 and A.7).

- The Gini Weight for the MDP technique is 0.63, while its respective Gini Risk posted 0.63 which also suggests this portfolio is fairly highly concentrated (see Figure A.6).

Figure 3 depicts the out-of-sample cumulative returns of the low volatility portfolios, together with the ALSI and SWIX indices. From Figure 3, one notices that most strategies tend to move in sync with each other. For example the EW, MDP, ERC and NRP techniques respectively are found to move together to a large degree. Importantly, all low volatility portfolios have outperformed the ALSI and the SWIX indices.

Similarly, Figure 4 depicts the risk-return positions of the low volatility portfolios, together with the ALSI and the SWIX indices. From Figure 4, it is evident that the Lowbeta, MVP, SIM, MDP, and the ERC portfolio, posted lower risks but also higher returns over the sample period. This is similar to the results of Clarke et al. [11], Clarke et al. [12], Maillard et al. [29], Choueifaty \& Coignard [7], Baker et al. [2], Khuzwayo [21] and Velvadapu [44] who all found that low volatility portfolios have outperformed the market capitalization portfolios over time. 


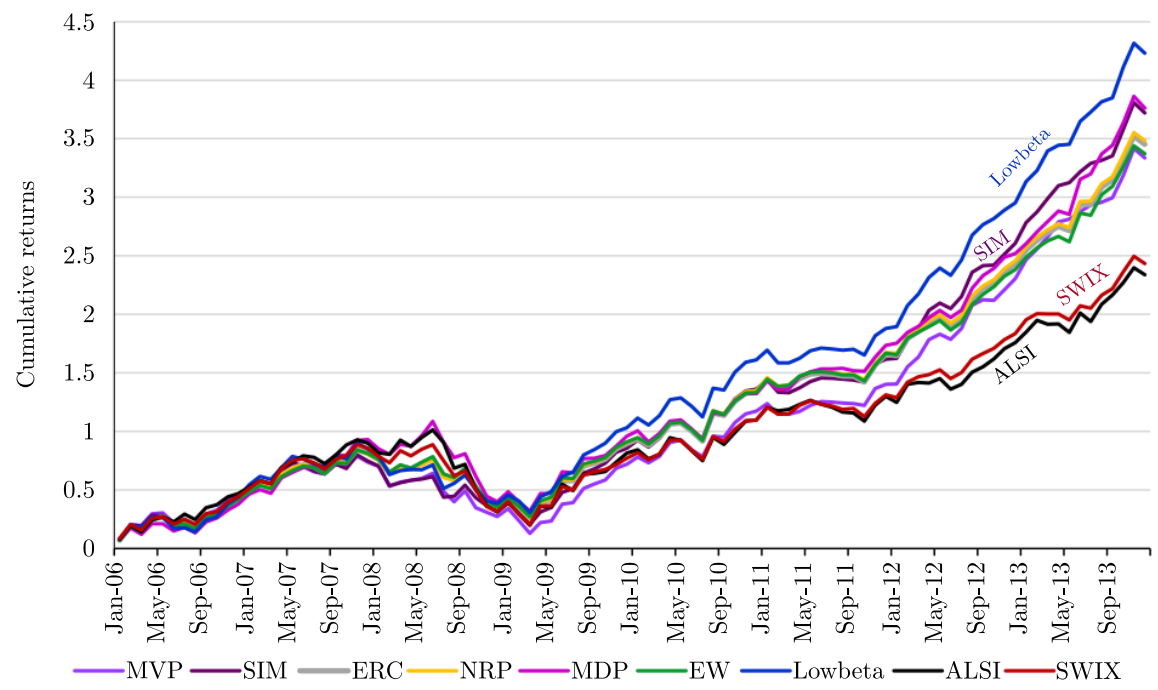

Figure 3: Out-of-sample cumulative returns of the FTSE/JSE sector-based low volatility portfolios January 2006-December 2013.

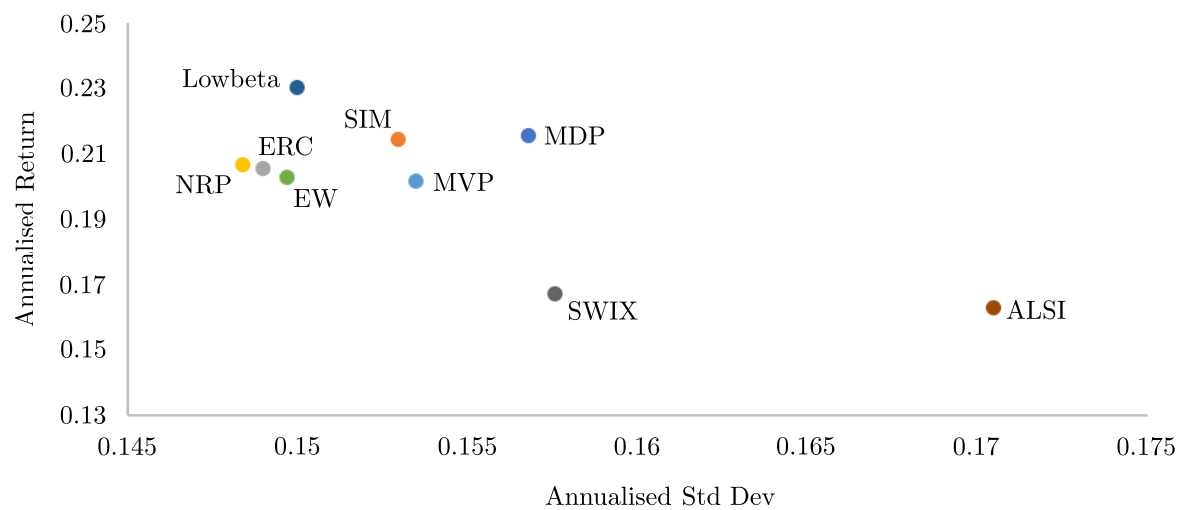

Figure 4: Risk-return plot of the sector-based low volatility portfolios, January 2006-December 2013.

To gain more insight into the performance of the low volatility strategies in various market regimes, the period is divided into 2 equal sub-periods, each having distinct market regimes. The first period (1 January 2006 to 31 December 2009) contained the period of the financial crises, whilst the second sub-period (1 January 2010 to 31 December 2013) characterised the market recovery period. Table 4 shows the cumulative return of each of the strategies (including the ALSI and SWIX) in each sub-period.

In sub-period 1 of Table 4 (characterized by the financial crisis) all the low volatility strategies, with the exception of the MVP strategy, outperformed both the ALSI and the SWIX. In the second sub-period (characterized by the market recovery), all of the lowvolatility strategies again outperform the ALSI and SWIX benchmarks, suggesting that the general outperformance of the low volatility strategies seem to have been consistent across market regimes. 


\begin{tabular}{lrrrrrrrrr}
\hline Return period & MVP & SIM & ERC & NRP & MDP & EW & Lowbeta & ALSI & SWIX \\
\hline $2006-2009$ & $72 \%$ & $86 \%$ & $89 \%$ & $90 \%$ & $96 \%$ & $91 \%$ & $103 \%$ & $82 \%$ & $77 \%$ \\
$2010-2013$ & $327 \%$ & $302 \%$ & $269 \%$ & $268 \%$ & $274 \%$ & $256 \%$ & $280 \%$ & $178 \%$ & $198 \%$ \\
\hline
\end{tabular}

Table 4: Out-of-sample cumulative return performance for the 2 sub-periods.

\section{$5 \quad$ Blending of sector-based low volatility portfolios}

Having assessed the performance of the low volatility portfolios under the constraint of full investment, one could imagine that active portfolio managers are unlikely to invest all their capital in these low volatility portfolios. Active managers typically have an invest style to generate active returns that they market to clients and are consequently more likely to want to enhance their risk-return performance by tilting towards low volatility portfolios, rather than to invest fully in them.

The blended portfolios are constructed by taking a combination of $X \%$ in the SWIX index $(1-X) \%$ in the low volatility portfolios. The SWIX index is chosen as a proxy for typical general equity portfolios. The SWIX was selected as it is closer to typical general equity portfolios, having a lower tracking error to the peer mean of general equity unit trusts, than the ALSI has. Empirical results of these blended portfolios are included for investing a limited range of scenarios, of $10 \%, 40 \%$, and $50 \%$ in the low volatility portfolios, while respectively investing $90 \%, 60 \%$, and $50 \%$ in the SWIX index. These blends were chosen on an ad hoc basis noting that it is unlikely that professional fund managers would allocate more than $50 \%$ of the low volatility strategy to their existing strategies For the select strategies (SIM and Lowbeta) a more comprehensive range of investment scenarios (blends) are considered.

Figures 5, 6 and 7 depict the risk return analysis of the 50-50, 40-60, and 10-90 blended portfolios and the SWIX. The MVP, SIM, ERC, NRP, EW, MDP, Lowbeta portfolios are appended with its respective blends (for example, MVP50.50 denotes the minimum variance portfolio blended with the SWIX). Whilst it is obvious that blending the SWIX with the low volatility portfolios will result in blended portfolios having superior returns and risks than the SWIX (because the SWIX has lower returns and higher risks than the low volatility portfolios), it is nevertheless shown that the positions of these returns in return-risk space to highlight the sorts of advantages that are achievable through blending.

The degree of outperformance achievable by combining the low volatility portfolios with a typical general equity portfolio as proxied by the SWIX can be established from Figures 5, 6 and 7. The Lowbeta and SIM blended portfolios posted the highest return-to-risk ratios. Table 5 depicts the descriptive statistics of the blended portfolios.

From Table 5, it follows that the Lowb50:50, SIM50:50, Lowb40:60, and SIM40:60 produced the highest Annualised Sharpe Ratio (1.306, 1.281, 1.261, and 1.243 respectively). Furthermore, they also produced the lowest drawdown when compared with the other blended portfolios. Looking at the performance of the Lowbeta and the SIM blended portfolios, Figure 8 depicts the out-of-sample cumulative returns, together with the SWIX index. 


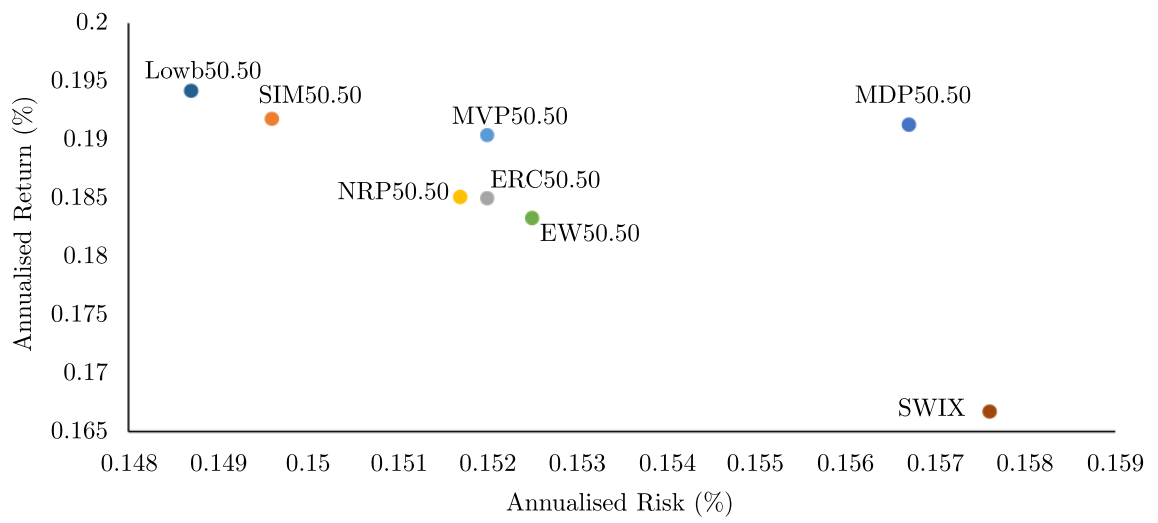

Figure 5: Scatter plot representing sector-based 50:50 blended with the SWIX index.

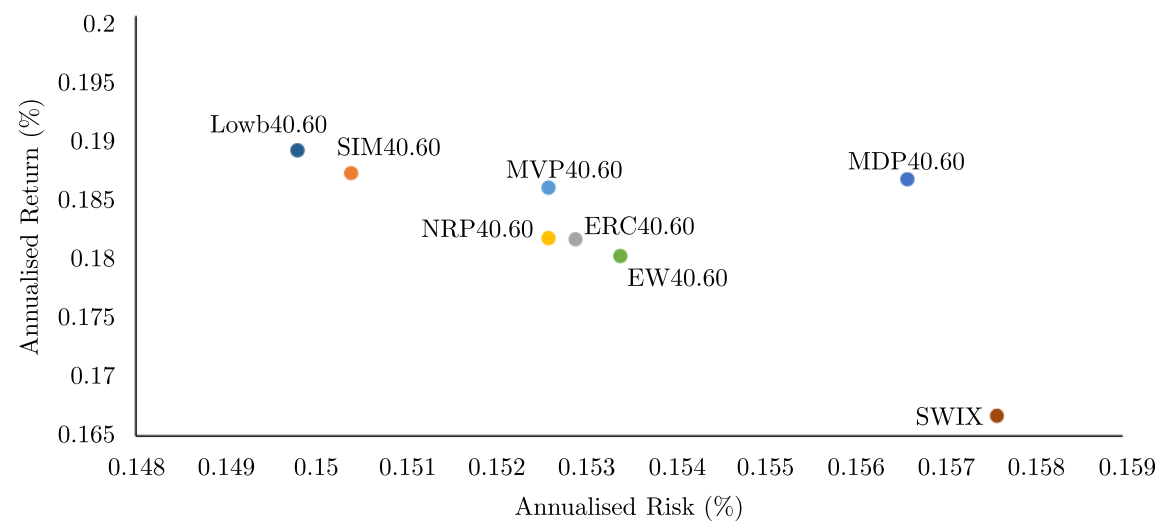

Figure 6: Scatter plot representing sector-based 40:60 blended with the SWIX index.

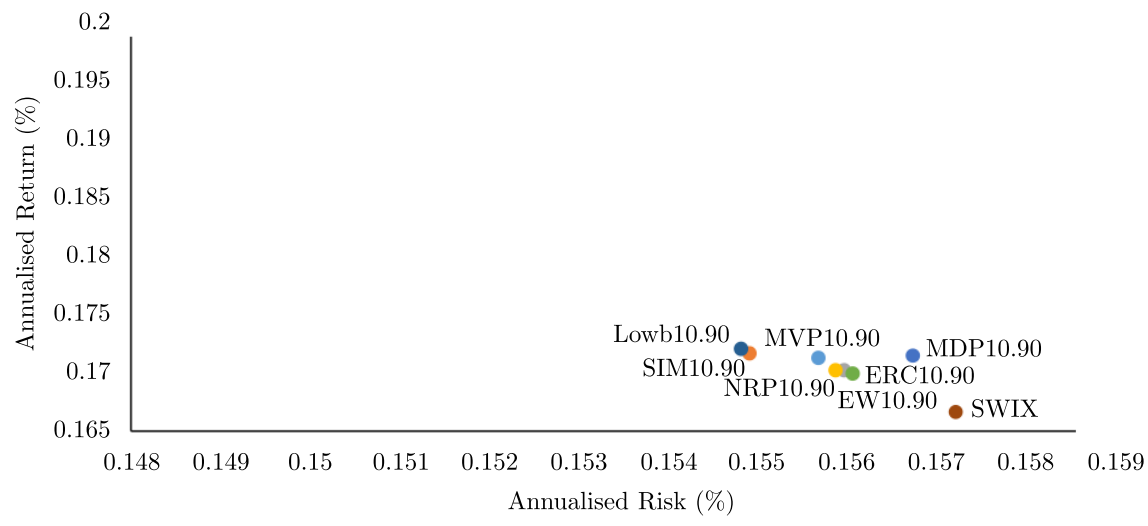

Figure 7: Scatter plot representing sector-based 10:90 blended with the SWIX index.

From Figure 8, it is evident that the blended portfolios have all outperformed the SWIX index. In addition, one notices that the SIM50:50, Lowb50:50, SIM40:60, and the Lowb40.60 tends to move in sync with each other over the sample period. To establish how the blended 


\begin{tabular}{rrrrr}
\hline SWIX BLEND & $\begin{array}{r}\text { Annualised } \\
\text { return }\end{array}$ & $\begin{array}{r}\text { Annualised } \\
\text { risk }\end{array}$ & $\begin{array}{r}\text { Annualised } \\
\text { Sharpe Ratio }\end{array}$ & Drawdown \\
\hline SIM10:90 & $17 \%$ & $16 \%$ & 0.5 & $36 \%$ \\
SIM40:60 & $19 \%$ & $15 \%$ & 0.61 & $35 \%$ \\
SIM50:50 & $19 \%$ & $15 \%$ & 0.64 & $34 \%$ \\
Lowb10:90 & $17 \%$ & $16 \%$ & 0.51 & $36 \%$ \\
\hline Lowb40:60 & $19 \%$ & $15 \%$ & 0.63 & $34 \%$ \\
Lowb50:50 & $19 \%$ & $15 \%$ & 0.66 & $33 \%$ \\
\hline NRP10:90 & $17 \%$ & $16 \%$ & 0.49 & $36 \%$ \\
NRP40:60 & $18 \%$ & $15 \%$ & 0.57 & $35 \%$ \\
NRP50:50 & $19 \%$ & $15 \%$ & 0.59 & $34 \%$ \\
MVP10:90 & $17 \%$ & $16 \%$ & 0.5 & $36 \%$ \\
MVP40:60 & $19 \%$ & $15 \%$ & 0.59 & $36 \%$ \\
\hline MVP50:50 & $19 \%$ & $15 \%$ & 0.63 & $36 \%$ \\
ERC10:90 & $17 \%$ & $16 \%$ & 0.49 & $36 \%$ \\
ERC40:60 & $18 \%$ & $15 \%$ & 0.57 & $35 \%$ \\
ERC50:50 & $19 \%$ & $15 \%$ & 0.59 & $34 \%$ \\
MDP10:90 & $17 \%$ & $16 \%$ & 0.49 & $37 \%$ \\
\hline MDP40:60 & $19 \%$ & $16 \%$ & 0.58 & $37 \%$ \\
MDP50:50 & $19 \%$ & $16 \%$ & 0.61 & $37 \%$ \\
\hline EW10:90 & $17 \%$ & $16 \%$ & 0.49 & $36 \%$ \\
EW40:60 & $18 \%$ & $15 \%$ & 0.56 & $34 \%$ \\
\hline EW50:50 & $18 \%$ & $15 \%$ & 0.58 & $34 \%$ \\
\hline
\end{tabular}

Table 5: A summary of the descriptive statistics of the blended portfolios.

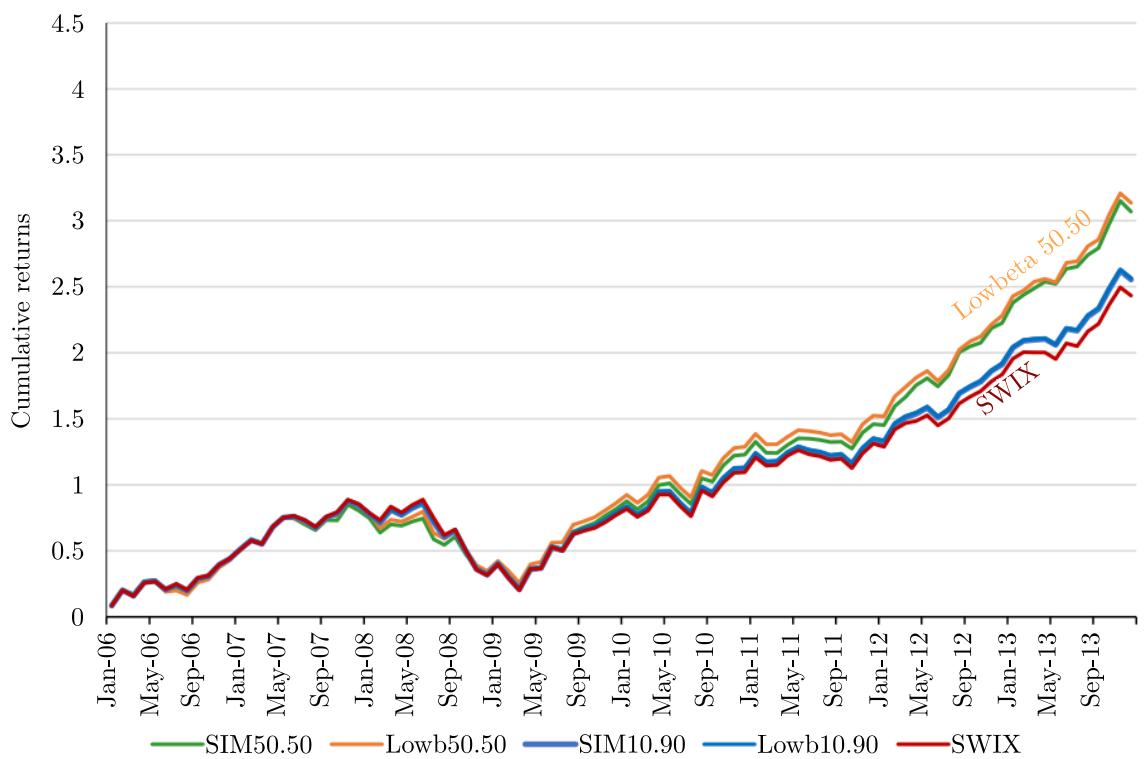

Figure 8: Out-of-sample performance of the top 2 blended portfolios for January 2006 to December 2013.

portfolios perform across the entire range of possible investment allocations, it is once more focused on the SIM and Lowbeta strategies. Table 6 depicts the proportion of Lowbeta and SIM low volatility portfolios across a more complete range of blended scenarios, together with their annualised risks. Similarly, the annualised standard deviation is also 
plotted against the blended proportions invested in the SIM and the Lowbeta portfolios separately in Figure 9.

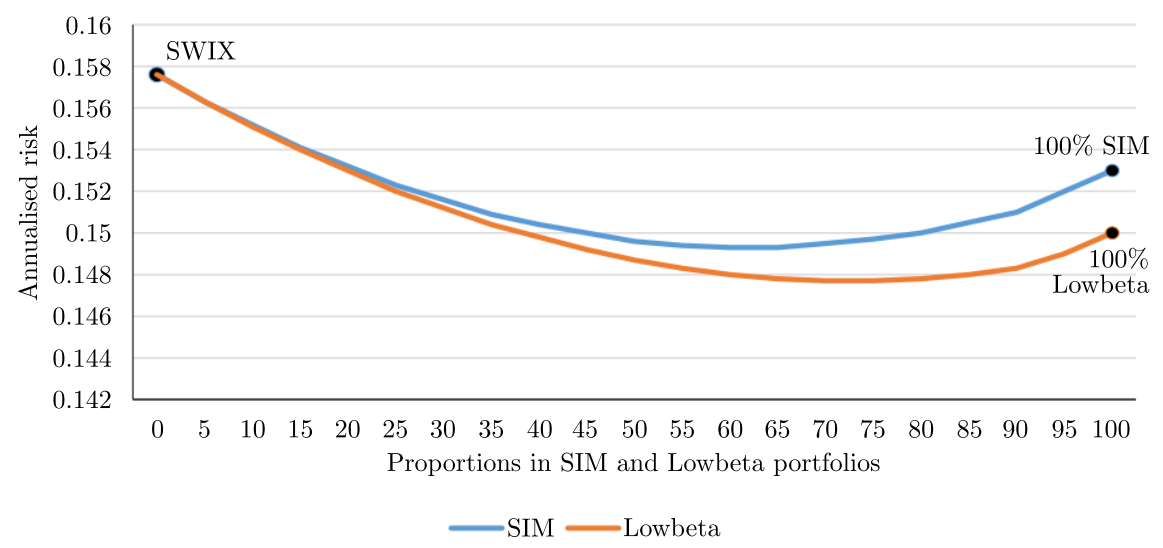

Figure 9: Annualised risk plot of the SIM and Lowbeta blended portfolios.

\begin{tabular}{rrr}
\hline $\begin{array}{r}\text { Proportion in the } \\
\text { portfolios }\end{array}$ & $\begin{array}{r}\text { Annualised risk } \\
\text { SIM }\end{array}$ & $\begin{array}{r}\text { Annualised risk } \\
\text { Lowbeta }\end{array}$ \\
\hline 0 & 0.157 & 0.157 \\
5 & 0.156 & 0.156 \\
10 & 0.155 & 0.155 \\
15 & 0.154 & 0.154 \\
20 & 0.153 & 0.153 \\
25 & 0.152 & 0.152 \\
30 & 0.152 & 0.151 \\
35 & 0.151 & 0.150 \\
40 & 0.150 & 0.150 \\
45 & 0.150 & 0.149 \\
50 & 0.150 & 0.149 \\
55 & 0.149 & 0.148 \\
60 & 0.149 & 0.148 \\
65 & 0.149 & 0.148 \\
70 & 0.150 & 0.148 \\
75 & 0.150 & 0.148 \\
80 & 0.150 & 0.148 \\
85 & 0.151 & 0.148 \\
90 & 0.151 & 0.148 \\
95 & 0.152 & 0.149 \\
100 & 0.153 & 0.150 \\
\hline
\end{tabular}

Table 6: Annualised risk of the SIM and Lowbeta blended portfolios

From Table 6 and Figure 9 it is evident that a move away from the SWIX towards a larger proportion of the SIM and Lowbeta portfolios in the blended portfolios, the risk of the blended portfolios reduce to a point where a minimum risk combination exists between the SWIX and low volatility blend. The risk of the blend turns out to be lower than either the risk of the SWIX or the low volatility portfolio in a region around the minimum risk combination. This occurs because the correlation and variance conditions of the SWIX and low volatility strategy portfolio is favourable for risk reduction beyond either risk of the 
two portfolios. Ultimately as one moves towards a $100 \%$ allocation in the low volatility strategy, risk again begins to increase as one moves beyond the minimum risk point. One could therefore conclude that for the SIM portfolio, the least annualised risk occurs approximately at the SIM55:45, SIM60:40, and the SIM65:35 blended portfolios. In the same vein, for the Lowbeta portfolio, the lowest annualised risk occurs when investing in the Lowb55.45 blend, and starts to increase again as one moves towards the Lowbeta90:10 blend.

\section{Conclusion}

In this article, seven low-volatility construction techniques were assessed using sectors as building blocks in South African markets. These portfolios were rebalanced annually and their performances were compared with a market capitalization-weighted index (ALSI). The performance of the low volatility portfolios was discussed, blended with the SWIX index to assess their usefulness as effective combined portfolio strategies. From the results it follows that

1. all the sector-based low volatility portfolios outperformed the ALSI at significantly lower risk, resulting in higher risk-adjusted returns,

2. the low-volatility portfolios posted a lower drawdown when compared with the ALSI, which implies that they can recover from losses quicker than the ALSI, and

3. blending low-volatility portfolios with typical market-capitalization weighted portfolios can serve as realistic and effective portfolio strategies.

Notably, it was evident that the Lowbeta and SIM portfolios have consistently been the superior performers of the low volatility portfolios throughout the sample period. It was also demonstrated that the benefit of the resulting low volatility portfolios could further enhance performance of typical portfolios such as the SWIX when such typical portfolios were blended with low volatility portfolios. It is thus recommended that either of these two low-volatility strategies be utilised in practice for constructing low-volatility portfolios in the South African environment.

\section{References}

[1] Arnott RD, Hsu J \& Moore P, 2005, Fundamental indexation, Financial Analysts Journal, 61(2), pp. 83-99.

[2] Baker M, Bradley B \& Wurgler J, 2011, Benchmarks as limits to arbitrage: Understanding the low-volatility anomaly, Financial Analysts Journal, 67(1), pp. 40-54.

[3] BlaCK F, 1972, Capital market equilibrium with restricted borrowing, The Journal of Business, 45(3), pp. $444-455$.

[4] Bradfield D \& Kgomari W, 2004, Concentration-should we be mindful of it, Research Report, Cape Town, Cadiz Quantitative Research.

[5] Carvalho RLD, Lu X \& Moulin P, 2012, Demystifying equity risk-based strategies: A simple alpha plus beta description, Journal of Portfolio Management, 38(3), pp. 56-70. 
[6] Chopra VK \& Ziemba WT, 1993, The effect of errors in means, variances, and covariances on optimal portfolio choice, The Journal of Portfolio Management, 19(2), pp. 6-11.

[7] Choueifaty Y \& Coignard Y, 2008, Toward maximum diversification, The Journal of Portfolio Management, 35(1), pp. 40-51.

[8] Choueifaty Y, Froidure T \& Reynier J, 2013, Properties of the most diversified portfolio, Journal of Investment Strategies, 2(2), pp. 49-70.

[9] Chow Tm, Hsu J, Kalesnik V \& Little B, 2011, A survey of alternative equity index strategies, Financial Analysts Journal, 67(5), pp. 37-57.

[10] Clarke R, De Silva H \& Thorley S, 2006, Minimum-variance portfolios in the us equity market, Journal of Portfolio Management, 33(1), pp. 10-24.

[11] Clarke R, De Silva H \& Thorley S, 2011, Minimum-variance portfolio composition, Journal of Portfolio Management, 37(2), pp. 31-45.

[12] Clarke R, De Silva H \& Thorley S, 2013, Risk parity, maximum diversification, and minimum variance: An analytic perspective, Journal of Portfolio Management, 39(3), pp. 39-53.

[13] Connor G \& Korajczyk RA, 1988, Risk and return in an equilibrium apt: Application of a new test methodology, Journal of Financial Economics, 21(2), pp. 255-289.

[14] DeMiguel V, Garlappi L \& Uppal R, 2009, Optimal versus naive diversification: How inefficient is the $1 / n$ portfolio strategy?, Review of Financial Studies, 22(5), pp. 1915-1953.

[15] FAMA EF \& FREnch KR, 1992, The cross-section of expected stock returns, the Journal of Finance, 47(2), pp. 427-465.

[16] Frazzini A \& Lasse HP, 2011, Betting against beta, Working Paper, New York University, Available from http://www.top1000funds.com.

[17] Frazzini A \& Pedersen LH, 2014, Betting against beta, Journal of Financial Economics, 111(1), pp. $1-25$.

[18] Haugen RA \& BAKer NL, 1991, The efficient market inefficiency of capitalization-weighted stock portfolios, The Journal of Portfolio Management, 17(3), pp. 35-40.

[19] Haugen RA \& Heins AJ, 1975, Risk and the rate of return on financial assets: Some old wine in new bottles, Journal of Financial and Quantitative Analysis, 10(5), pp. 775-784.

[20] Jagannathan R \& Ma T, 2003, Risk reduction in large portfolios: Why imposing the wrong constraints helps, The Journal of Finance, 58(4), pp. 1651-1684.

[21] Khuzwayo B, 2011, Diversification in Portfolio Construction: Can it lead to outperformance?, Research Report, Cape Town, Cadiz Quantitative Research.

[22] Kritzman M, Page S \& Turkington D, 2010, In defense of optimization: the fallacy of $1 / n$, Financial Analysts Journal, 66(2), pp. 31-39.

[23] Kruger R, Strugnell D \& Gilbert E, 2011, Beta, size and value effects on the jse, 1994-2007, Investment Analysts Journal, 40(74), pp. 1-17.

[24] Kruger R \& Van Rensburg P, 2008, Evaluating and constructing equity benchmarks in the south african portfolio management context, Investment Analysts Journal, 37(67), pp. 5-17.

[25] Leclerc F, L'Her JF, Mouakhar T \& Savaria P, 2013, Industry-based alternative equity indices, Financial Analysts Journal, 69(2), pp. 42-56. 
[26] Ledoit O \& Wolf M, 2003, Honey, i shrunk the sample covariance matrix, UPF Economics and Business Working Paper, 30(4), pp. 110-119.

[27] LeE W, 2011, Risk-based asset allocation: A new answer to an old question?, Journal of Portfolio Management, 37(4), pp. 11-28.

[28] Lintner J, 1965, Security prices, risk, and maximal gains from diversification, The Journal of Finance, 20(4), pp. 587-615.

[29] Maillard S, Roncalli T \& Teïletche J, 2008, On the properties of equally-weighted risk contributions portfolios, Available from http://papers.ssrn.com.

[30] Maillard S, Roncalli T \& Teïletche J, 2010, On the properties of equally-weighted risk contributions portfolios, The Journal of Portfolio Management, 36(4), pp. 60-70.

[31] Markowitz H, 1952, Portfolio selection, The Journal of Finance, 7(1), pp. 77-91.

[32] Markowitz H, 1959, Portfolio selection: efficient diversification of investments, Basil Blackwall, New York (NY).

[33] Markowitz HM, 1976, Markowitz revisited, Financial Analysts Journal, 32(5), pp. 47-52.

[34] Merton RC, 1980, On estimating the expected return on the market: An exploratory investigation, Journal of financial economics, 8(4), pp. 323-361.

[35] Michaud RO, 1989, The markowitz optimization enigma: is' optimized'optimal?, Financial Analysts Journal, 45(1), pp. 31-42.

[36] Munro B \& Bradfield D, 2016, Putting the squeeze on the sample covariance matrix for portfolio construction, Investment Analysts Journal, 45(1), pp. 1-16.

[37] PANulo B, 2014, Risk parity and other risk based portfolio allocation approaches in south african and international equity markets, Masters Thesis, University of Cape Town.

[38] QIAN E, 2011, Risk parity and diversification, Journal of Investing, 20(1), pp. 119-129.

[39] Roll R \& Ross SA, 1994, On the cross-sectional relation between expected returns and betas, The Journal of Finance, 49(1), pp. 101-121.

[40] Sharpe WF, 1963, A simplified model for portfolio analysis, Management science, 9(2), pp. 277-293.

[41] Siegel LB, 2003, Benchmarks and investment management, Research Foundation Publications, Charlottesville, Virginia.

[42] Snopek L, 2012, The Minimum Variance Portfolio, pp. 223-225 in The Complete Guide to Portfolio Construction and Management, John Wiley \& Sons, Ltd., Available from http://dx.doi.org/10. 1002/9781118467220.ch34.

[43] van Rensburg P \& Robertson M, 2003, Style characteristics and the cross-section of jse returns, Investment Analysts Journal, 32(57), pp. 7-15.

[44] Velvadapu P, 2011, The evolution of equal weighting, Journal of Indexes, 14(1), pp. 20-29. 


\section{Appendix A: Evolution of FTSE/JSE sector weights and risk contributions}

Figures A.1-A.8 show the weights and risk contribution for the ALSI, MVP, SIM, ERC, NRP, MDP, EW and Lowbeta portfolios for different FTSE/JSE sectors.

ALSI

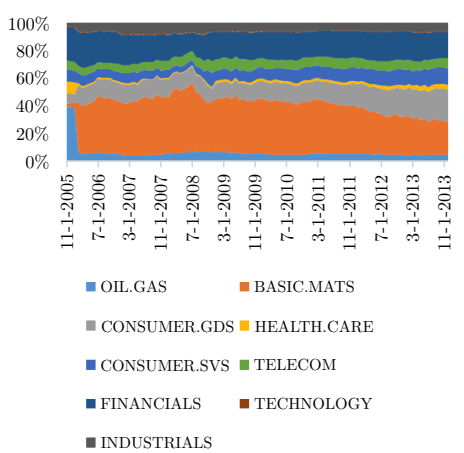

ALSI risk contribution

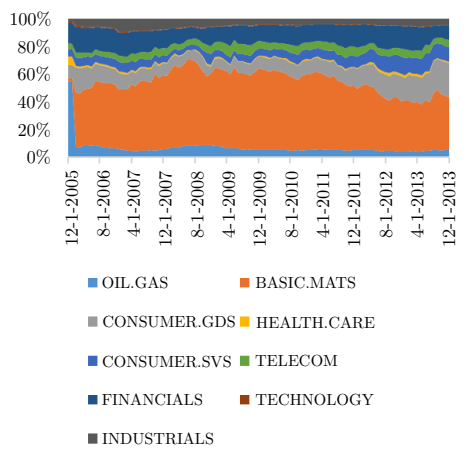

Figure A.1: FTSE/JSE weights (left) and risk contribution (right) for the ALSI.
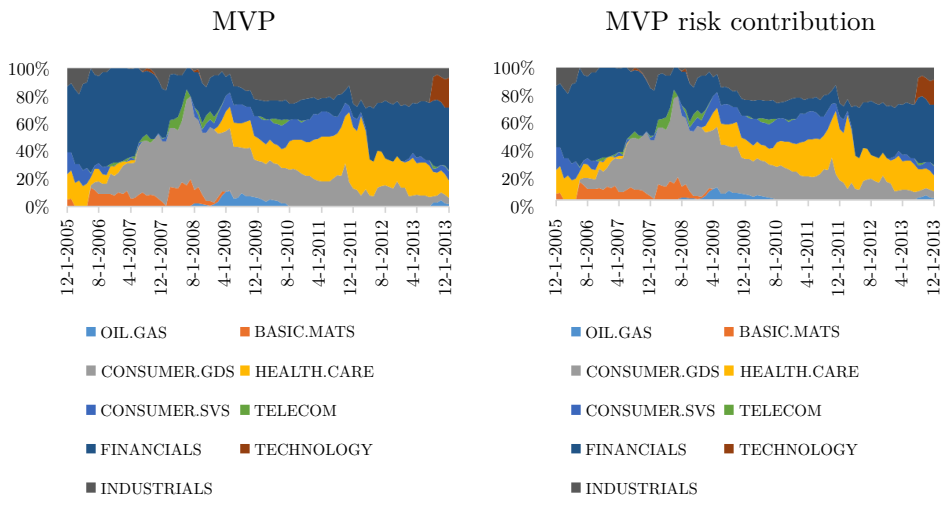

Figure A.2: FTSE/JSE weights (left) and risk contribution (right) for the Minimum Variance portfolio.

SIM

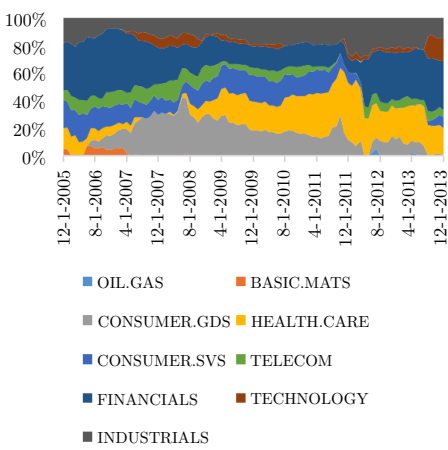

SIM risk contribution

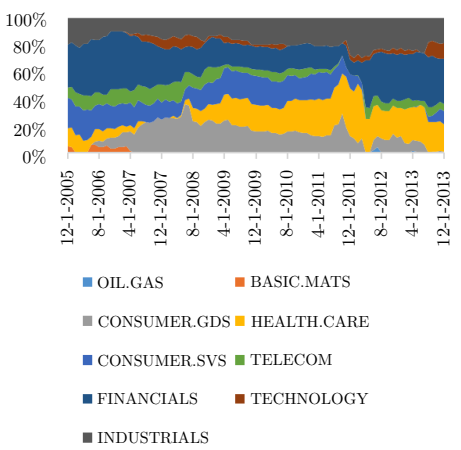

Figure A.3: FTSE/JSE weights (left) and risk contribution (right) for the Single Index Model. 
ERC

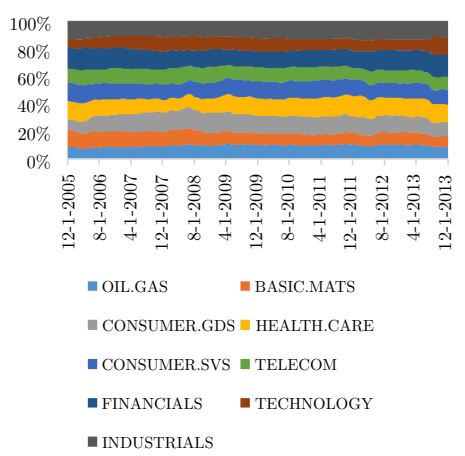

ERC risk contribution

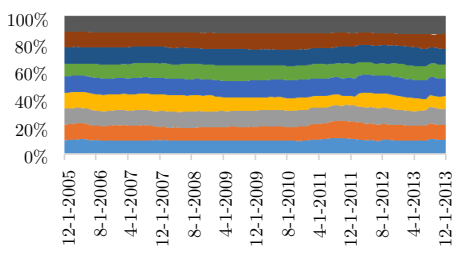

$\because$ OIL.GAS $\quad$ BASIC.MATS

m CONSUMER.GDS $\cong$ HEALTH.CARE

@ CONSUMER.SVS $\mathbf{m}$ TELECOM

- FINANCIALS - TECHNOLOGY

m INDUSTRIALS

Figure A.4: FTSE/JSE weights (left) and risk contribution (right) for the Equal risk contribution portfolio.

NRP

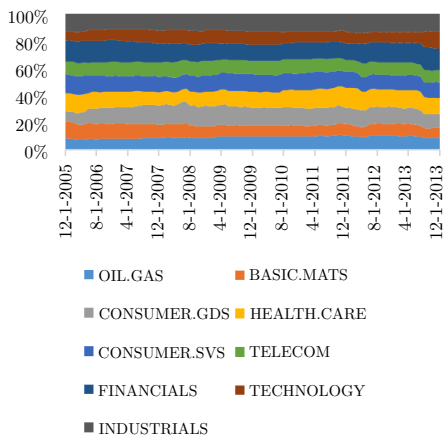

NRP risk contribution

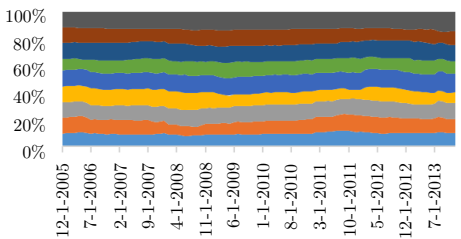

IIL.GAS BASIC.MATS

n CONSUMER.GDS $\square$ HEALTH.CARE

- CONSUMER.SVS $\square$ TELECOM

- FINANCIALS - TECHNOLOGY

- iNDUSTRIALS

Figure A.5: FTSE/JSE weights (left) and risk contribution (right) for the Naïve risk parity portfolio.
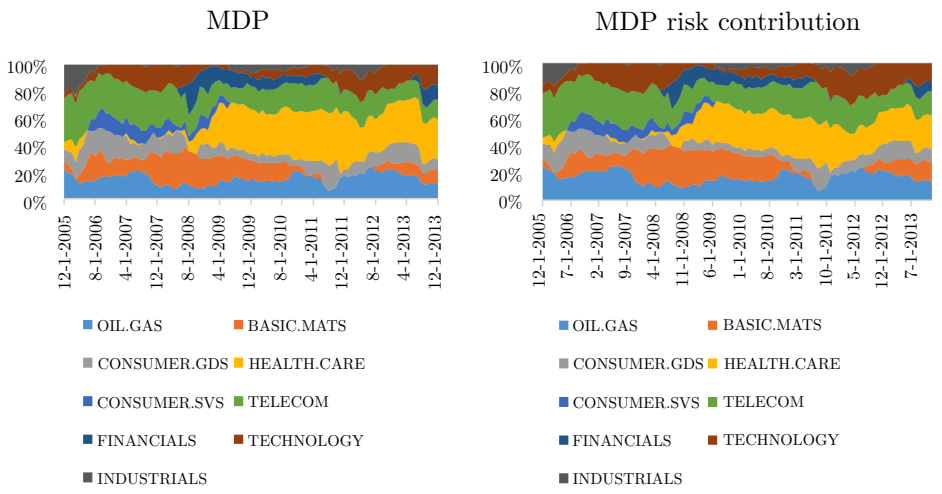

Figure A.6: FTSE/JSE weights (left) and risk contribution (right) for the Maximum Diversification portfolio. 
EW

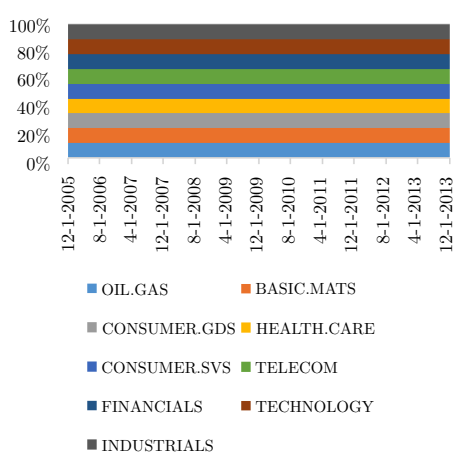

EW risk contribution

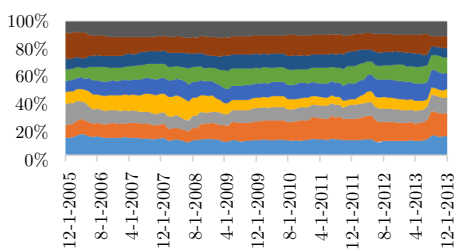

- OIL.GAS $\quad$ BASIC.MATS

— CONSUMER.GDS $\square$ HEALTH.CARE

- CONSUMER.SVS $=$ TELECOM

- FINANCIALS TECHNOLOGY

- INDUSTRIALS

Figure A.7: FTSE/JSE weights (left) and risk contribution (right) for the Equal weight by sectors portfolio.

Lowbeta

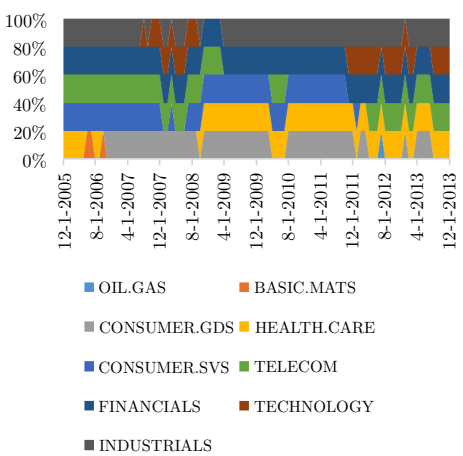

Lowbeta risk contribution

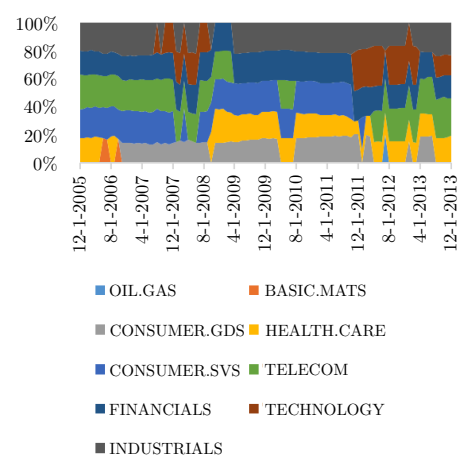

Figure A.8: FTSE/JSE weights (left) and risk contribution (right) for the Lowbeta Portfolio. 


\section{Appendix B: FTSE/JSE sector weights over the sample pe- riod $(2003-2013)$}

Tables 7 and 8 show the last known weight of the low volatility portfolios in 2013 and in brackets the average weight over the sample period.

\begin{tabular}{rrrrrr}
\hline & Oil and gas & Basic mats & Consumer goods & Health care & Consumer services \\
\hline ALSI & $0.06(0.05)$ & $0.35(0.240)$ & $0.15(0.240)$ & $0.020(0.030)$ & $0.080(0.120)$ \\
SIM & $0.001(0)$ & $0.007(0)$ & $0.16(0.008)$ & $0.18(0.188)$ & $0.116(0.08)$ \\
MVP & $0.014(0.018)$ & $0.032(0)$ & $0.236(0.046)$ & $0.159(0.125)$ & $0.07(0.064)$ \\
ERC & $0.096(0.088)$ & $0.094(0.074)$ & $0.126(0.103)$ & $0.122(0.128)$ & $0.116(0.109)$ \\
NRP & $0.092(0.086)$ & $0.091(0.072)$ & $0.127(0.106)$ & $0.121(0.116)$ & $0.119(0.117)$ \\
MDP & $0.148(0.121)$ & $0.114(0.091)$ & $0.108(0.083)$ & $0.213(0.297)$ & $0.033(0)$ \\
EW & $0.111(0.111)$ & $0.111(0.111)$ & $0.111(0.111)$ & $0.11(0.111)$ & $0.111(0.111)$ \\
Lowbeta & $0.002(0)$ & $0.006(0)$ & $0.132(0)$ & $0.146(0.2)$ & $0.138(0)$ \\
\hline
\end{tabular}

Table 7: The FTSE/JSE sector weights over the sample period (2003-2013) for oil and gas, basic mats, consumer goods, health care and consumer services.

\begin{tabular}{rrrrr}
\hline & Telecom & Financials & Technology & Industrials \\
\hline ALSI & $0.070(0.070)$ & $0.2(0.190)$ & $0.005(0.003)$ & $0.07(0.06)$ \\
SIM & $0.07(0.055)$ & $0.268(0.355)$ & $0.031(0.166)$ & $0.167(0.146)$ \\
MVP & $0.011(0.006)$ & $0.325(0.454)$ & $0.011(0.219)$ & $0.143(0.068)$ \\
ERC & $0.101(0.092)$ & $0.134(0.159)$ & $0.089(0.129)$ & $0.123(0.118)$ \\
NRP & $0.098(0.086)$ & $0.138(0.163)$ & $0.088(0.125)$ & $0.127(0.129)$ \\
MDP & $0.207(0.147)$ & $0.045(0.106)$ & $0.101(0.153)$ & $0.03(0)$ \\
EW & $0.111(0.111)$ & $0.111(0.111)$ & $0.111(0.111)$ & $0.111(0.111)$ \\
Lowbeta & $0.134(0.2)$ & $0.2(0.2)$ & $0.07(0.2)$ & $0.171(0.2)$
\end{tabular}

Table 8: The FTSE/JSE sector weights over the sample period (2003-2013) for telecom, financials, technology and industrials. 